\title{
Technological and social networks of a pastoralist artificial society: agent-based modeling of mobility patterns
}

\author{
Juan Miguel Rodriguez-Lopez ${ }^{1}$ (D) Meike Schickhoff $^{2} \cdot$ Shubhankar Sengupta $^{3}$. \\ Jürgen Scheffran ${ }^{1}$ (D)
}

Received: 10 June 2020 / Accepted: 21 December 2020 / Published online: 3 February 2021

(c) The Author(s) 2021

\begin{abstract}
This paper explores the advantages of simulation to raise the question of how digital and social networks affect the mobility in a pastoralist artificial society in the context of environmental degradation. We aim to explore mechanisms and develop scenarios, which are going to be validated through further research. We use a model of a simple pastoralist society in a world without borders to migration by adding the possibility of experiencing the effects of social structures (such as family and friends) and technological networks (e.g., social media). It appears obvious that pastoralist mobility depends on other dimensions as land tenure and traditional knowledge; however, isolating these two effects and experimenting in a simple society allow us to filter the multidimensionality of mobility decisions and concentrate on comparing scenarios in several different social structures and technological network combinations. The results show an expected behavior of more connection and more mobility, and a non-linear emergent behavior where pastoralists wait for a longer amount of time to mobilize when they interact using powerful social and technological networks. This occurs until they decide to move, and then, they mobilize more quickly and strongly than they did when communication was non-existent between them. The literature on migration explains this emergent non-linear behavior.
\end{abstract}

Keywords Mobility $\cdot$ Networks · Agent-based modeling $\cdot$ Pastoralism · Environmental degradation

\section{Introduction}

Freedom of movement is defined as a human right (Universal Declaration of Human Rights, Article 13); however, this principle is far from being respected, or even accepted, as a model for a desirable future society. Pastoralists face

Juan Miguel Rodriguez-Lopez

miguel.rodriguez@uni-hamburg.de

Extended author information available on the last page of the article 
increasing constraints to land access [23], specifically due to changes in land tenure and land-use systems (e.g., expansion of agricultural areas, new natural conservation areas, and land fragmentation) which affect the widespread pastoralism in sub-Saharan Africa [38, 39]. Their social networks are an important asset of pastoralists representing social interaction and cascade effects [12], and nonlinear behavior such as steam and counter-steam [68]. Moreover, environmental degradation increases restrictions and pressure to provide water and feed (pastures) [20]. However, there have recently been positive developments for pastoralists. New technologies, in particular cellular phones, have increased income in Africa in 2011 by an estimated 3.5\% of Gross Domestic Product [14] for these specific communities of pastoralists, because they allow decisions to be made with current information, reducing market, and climatic risks [20]. The pastoralist economy can be divided into production (herding) and trading. Regarding the commercial aspect, the use of cellular phones has been well studied and shown to increase and optimize livestock trades, but, for herders, it may not lead to more efficient management of resources [14]. There are several reasons to explain this phenomenon. Cellular phones, while widely used by pastoralists, are complementary and not a substitute for the local social structures when obtaining information. Moreover, herders may not have discovered the full potential of this technology yet $[14,20]$. New research is needed about the way pastoralists exercise their right to mobility in a world with resource restrictions, where the largest flow of information occurs in a context of complementarity between local social structures, like families and ethnic groups, and how the cellular phone acts as a form of digital network. Our modeling approach is based upon the so-called "Sugarscape" model, which was designed by Epstein and Axtell [26] and experimented with a simple seasonal mobility, showing that agents mobilize in a restricted area (one hill) or they hibernate [26]. We have given actors the possibility to communicate between them which opens this well-known model to the research on mobility and migration, because the actors start to look for other territories outside of their own hills.

In this research, we implement an artificial world with resource constraints facing environmental degradation and analyze how different forms of networks affect mobility using analysis elements of mobile agents, migration theory, and the impact of new technologies. Facing environmental degradation, the pressure to increase mobility becomes greater in a pastoralist world. Therefore, we focus on this as a starting point for our simulation. We are aware of the complexity of mobility decisions in the context of pastoralism. Nevertheless, we argue that agent-based modeling is an appropriate tool for modeling mobility rules that produce complex results [57]. Our main contribution is showing the ability of interdisciplinary efforts combining pastoralism, networks, and agent-based modeling to generate answers to complex questions with new network technologies for herders under an agent-based perspective. Moreover, this paper provides disciplinary contributions showing how these simple rules of mobility can reach complex results and adding knowledge to the several literature streams. As an example for the pastoralism literature, the effect of new technology matters for networks of pastoralists helping them to more quickly discover new land, but it does not 
generate a major change of the results. To the network literature, we present a first implementation of a network model from an agent-based perspective, which replicates existing research results like for example stream and counter stream as contributions [68]. Also, this paper shows that the networked actors become more active instead of hibernating as in the seminal model of Epstein and Axtell [26], adding to the agent-based modeling literature. Following the methodological principles of complex social simulation $[8,18]$, this research fulfills the needed conditions (socio-techno-natural, multi-scale, and multi- and inter-disciplinary complexity) to be considered an "initial model M0" as the literature points out [18] and it has been implemented in Netlogo 6.0.4.

The main assumption of this study is that human mobility is a complex process. It results from an intricate decision-making, and depends on the socio-economic and political situation as well as on social and societal structures, which vary over time and space. This makes it difficult to capture migration and mobility in one single comprehensive theory. For this reason, we draw on insights of different theories, which focus on specific aspects of mobility and migration.

Parallels exist between South-South migration theory and mobility of pastoralist groups. New empirical evidence shows that the largest migratory flows occur between South and West Asia, within Africa and from Latin America to North America [1]. This fact contradicts many hidden assumptions of traditional migration theory, since "migration" is often connoted as Global South-to-Global North movement [58]. In particular, the largest migration flows demonstrate that global migration has a strong South-South character and needs to be reexamined, because the traditional drivers of migration do not provide an answer for this phenomenon that is potentially significant [1]. A major point of South-South migration theory is that social structures have a more important role and borders play a lesser role, which is a growing field of research $[58,69]$. This view could be complemented by the "new paradigm of mobilities" [40, 70] and questions the traditional perspective to view standstill and sedentary behavior as normal and migration as deviating from this. In contrary, it illustrates how mobility and interconnectedness has always been a part of human living conditions [35]. To explicitly account for the facts that mobility is a consistent part of human life and that most migration movements take place as south-south, in this study, we use the more general term "mobility" instead of "migration" and understand it as human mobility.

Networks are crucial for changing one's place of residence [13, 55]. Massey [52] defines mobility networks as "sets of interpersonal ties that link migrants, former migrants, and non-migrants in origin and destination areas through the bonds of kinship, friendship, and shared community origin." [52]. Besides, the social networks are made up of family, friendship, and community ties to be the key components of mobility systems [13]. Family members are reliable and trustworthy sources of information, since communication with them is among the most effective. Also, the stronger the emotional bonds, the easier it is to maintain them over long distances $[19,37,44,50]$. Furthermore, obligations to family members are long-lasting and thus have a significant impact on mobility. For instance, this might include sponsorship for new immigrants [28]. Family ties are considered as typically strong ties, 
since they embody a strong emotional bond. Weak ties, by contrast, involve connections between people who only meet occasionally.

To base our research on a well-documented society with resource constraints to mobility, we draw on the literature of pastoralists who-for the most part-experience this kind of world. Pastoralists mostly live in drylands and substantially rely on raising livestock to meet their nutritional needs [30, 60]. Many of the regions inhabited in this way show very variable rainfall patterns, and thus, natural resources are often scarce and highly fluctuating [23]. These harsh conditions are deteriorated by climate change inducing more frequent droughts and floods [31].

Due to the dependence on spatially and temporally variable resources such as pasture and water for their livestock, pastoralists adapt to the environmental conditions by various strategies. Mobility of various time and spatial scales is a crucial part of adaptation and ranges from moving herds around the campsite to seasonal displacements to other ecological areas [64]. The decision on when and where to move usually depends on the forage and water quality and quantity but also on the presence of diseases and park patrols, among others. To gather and exchange this information, social networks are of crucial relevance [14]. Particularly kinship-based groups are important, since they serve as an organization structure in many pastoralist societies [66]. Information concerning the health and well-being of the livestock is shared with family members [14]. Also access rights to pasture are often organized according to kin-based groups [7], while information related to herding strategies and grazing locations is shared not only within kinship networks [14].

The recent technological developments offer further possibilities concerning information networks. Especially, the use of cellular phones has proven to be invaluable to gather up-to-date information on water and pasture quality, locations and market conditions, and the weather forecast [23]. Before moving to a specific location, pastoralists often phone ahead to family or friends to estimate the environmental conditions. This saves time, reduces travel costs, and avoids going to deteriorated areas. In addition, the market conditions can be better estimated gathering information via cellular phones. These advantages may be narrowed by poor network coverage. Pastoralists cope with these problems by calling from elevated areas or hanging their phones on high objects to improve connectivity [20]. Others carry multiple SIM cards at once to be able to switch to the best-working network [14]. The technology-related difficulties are expected to decrease in the near future [42]. Furthermore, many of the important deep wells are situated close to villages with good network coverage which positively affects pastoralist information exchange [20]. Besides, our results show that high or low contact regularity (as frequency with which agents come into contact) does not play a major role in the mobility behavior (see Results section). Thus, with new technologies, pastoralists can make more informed decisions and reduce their livelihood risks despite not yet extensive network coverage in all areas [20]. This simulated world allows us to examine social and digital effects together to analyze their combined effect being more than the sum of the individual contributions of social and technological ties. Therefore, we have as main supposition: the stronger the joint social and technological ties, the greater the mobility. However, it is relevant for the research question of how different forms of networks affect mobility to differentiate the effects. 
Ethnic and religious groups as well as professional associations are considered as weak-tie networks. Usually, they are based on some kind of common interest or solidarity with each other [27] and this is relevant when we are focusing on the role of ethnic networks $[13,16]$. For instance, associations based on ethnicity may act as a nexus for information, help, and social support. In the case of return mobility, they might also facilitate reintegration into the home community. Furthermore, ethnic networks also support economic adjustment, for instance through job sponsorship like employment in an ethnic restaurant [28]. Therefore, based on this literature, we can derive and anticipate supposition 1: the stronger the social ties, the greater the mobility.

The digital age provides new opportunities for staying in touch complementing the various forms of social networks. Online communication is fast, cheap, and media-rich, and allows distant contacts to become more intimate through the possibilities of sending photos, videos, and the use of video phone calls [47, 51]. Studies show that online media are indeed used as an important communication channel in mobility networks $[22,61]$ and that experiences of mobility in the digital age differ from former experiences [2]. Chain mobility is facilitated, since it is easier to find friends and relations abroad who might support one's journey and arrival [47].

Furthermore, the use of online media can amplify weak ties, since it is easily possible to connect with each other via Facebook or other social media without the need for spatial proximity. Thus, it is easy to revive old contacts and to expand the network of weak ties throughout the journey $[21,61,75]$. This allows access to a broad range of information. If a person only stays within his/her close circle of friends and family, the possibilities to gather new information are much fewer than if the person connects with various acquaintances from different backgrounds [36]. These insights support the assumption that digital networks offer better quality and more up-to-date information as well as low to zero communication costs. The advantages of mobile phone usage have shown to have a positive impact on mobility even if areas without coverage lie within the journey [67]. Therefore, supposition 2 is proposed as: the stronger the technological ties, the greater the mobility.

\section{Method}

\section{Agent-based modeling}

Agent-based modeling is a simulation method used in multidisciplinary fields like complexity science, computational sociology, and game theory [3]. In the social sciences, it is especially useful for modeling social interactions and networks, which makes it a popular tool in population and mobility studies [72]. The models are based on a set of heterogeneous and autonomous agents, which can act and interact, adapt to their environment, and learn [77]. They can be either individual entities or collective or aggregated units like organizations or groups [71]. The agent's actions and their relationships are based on decision algorithms which can be grounded on knowledge or available data [4] to facilitate robust simulations across a wide range of futures [63]. 


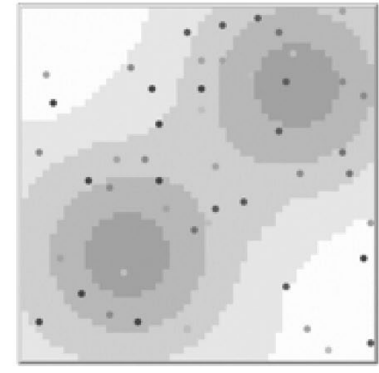

(a) Original model

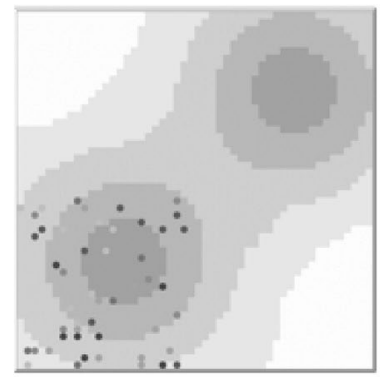

(b) Model with accumulation

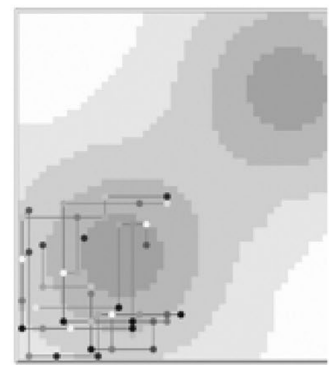

(c) Graphic with networks

Fig. 1 Adapting sugarscape to mobility

The aggregated individual attributes, actions, and interactions of the agents can lead to the emergence of societal phenomena on the macro-level, which are qualitatively different from the individual behavior [10,11]. Agent-based models excel at simulating interactions between the individual agents on the micro-level, societal structures on the macro-level, and social networks on the meso-level, as well as how these interactions lead to effects across these levels [65]. Furthermore, agent-based models are also used when space is crucial, or tipping points, cascade effects, or other non-linear effects are to be simulated [17, 77]. Usually, the aim of the models is to discover causal mechanisms [46].

\section{Sugarscape}

This study is based on the "Sugarscape" model, which was designed by Epstein and Axtell [26]. It is an abstract model, but is adequate to simulate basic societal processes [33]. The aim is not to transfer results directly to real human societies but rather to explore mechanisms and develop scenarios, which can be verified through further research. Sugarscape is a fairly general model which allows to simulate various social phenomena with little modification. There is already a simple seasonal mobility model implemented in Sugarscape, which shows that some agents move when winter comes, while other agents hibernate. Winter is represented by reduced resources [26].

The Sugarscape world is represented by a $50 \times 50$ cell grid and simulations are run for large time periods, in units of time called 'ticks', where one tick represents one complete cycle of the program. A landscape is simulated which consists of areas with different amounts of resources represented in sugar units and agents are placed in random form (see Fig. 1a). In our version of the Sugarscape world adapted to mobility, we concentrate all agents on one hill (Fig. 1b) and analyze what happens when the agents are interconnected with family and ethnic networks using a digital (quick and cheap transmission) or analog (slow and expensive transmission) technology (Fig. 1c) in their mobility behavior.

Sugar is the resource on which agents depend to survive, and can intuitively represent wealth, or in this case the quality of a location for grazing of livestock. To 
accumulate sugar, the sugar patch needs to lie within the vision of the agent. The vision of the agent is the ability to perceive the amount of resources (sugar) present on a given patch which can be situated vertically or horizontally (not diagonally at all) with respect to the position where the agent is located. Through the networks in our developed model, the agents are receiving more information about the resource distribution from the other related agents. The strength of vision as well as metabolism are randomly distributed genetic endowments. The metabolism states how much sugar the agent needs to eat per time step in order to survive. As it stands as a measure of resource usage per time, it can be taken to represent the size of the herd owned by a pastoralist. Therefore, pastoralists with a smaller herd, represented by a slower metabolism, can survive for longer from the same amount of sugar than those with faster metabolisms. If the sugar of one grid cell is accumulated by an agent, it turns to zero and regrows back to its maximum level within a specific time frame [26]. For a description of the model in Unified Modeling Language (UML), see Fig. 2. UML is the most common form of schematically diagramming models and extended used among computer scientists to increase the accuracy of modeling definition $[9,43]$. Each part of the diagram is defined by its function; for example, we have a super Class (World), and derived classes (Network, Agent and Patch). Each class has attributes (e.g., "metabolism" and "vision" for Agent class) and methods (e.g., "go" and "eat" for Agent Class), which are the actions that each class executes.

In the world of Sugarscape, resources are non-uniformly distributed, forming two 'hills' of sugar some distance apart. The distribution of sugar is highest at the centers of these hills, making them desirable targets for migration. Initially, agents live on only one of the sugar hills and in adjacent areas. The other hill is not yet inhabited and thus holds more resources. Environmental change is introduced via a slower regrowth rate of sugar. This will deteriorate the survival conditions of agents and thus substantially worsen their economic situation. As an adaptation strategy, agents can move around to harvest sugar in other, less occupied places. In situ adaptation is not possible in this model, so the degradation of the environment provides an impetus for the agents to move; thus representing the high dependence of pastoralists on the quality of their spatial location. To move, agents have to be able to afford the costs and risks of moving. The decision rule of the agents reads the following:

End the tick on a patch for which the value of utility A (for that patch) is maximized

The utility of a patch $P$ is calculated as $A=\left(\left(\right.\right.$ Income $_{P}-$ Income $\left._{P 0}\right)-$ costs - risks).

Where Income ${ }_{P}$ is the potential income at patch $P$, and Income In $_{P 0}$ is the income at the initial patch that the agent occupies at the beginning of the tick. Therefore, the agent seeks to maximize the gain in income at each tick, taking into account the costs and risks involved in achieving that gain.

At every unit of time, each agent evaluates the patches within their vision in terms of this utility A. The patch that offers the maximum amount of utility as per this rule is selected as the destination. It is also possible that the patch that offers the maximum utility is the one that the agent currently occupies, in which case it will not move. Since the mobility costs in such a case are zero, this ensures that the agent 


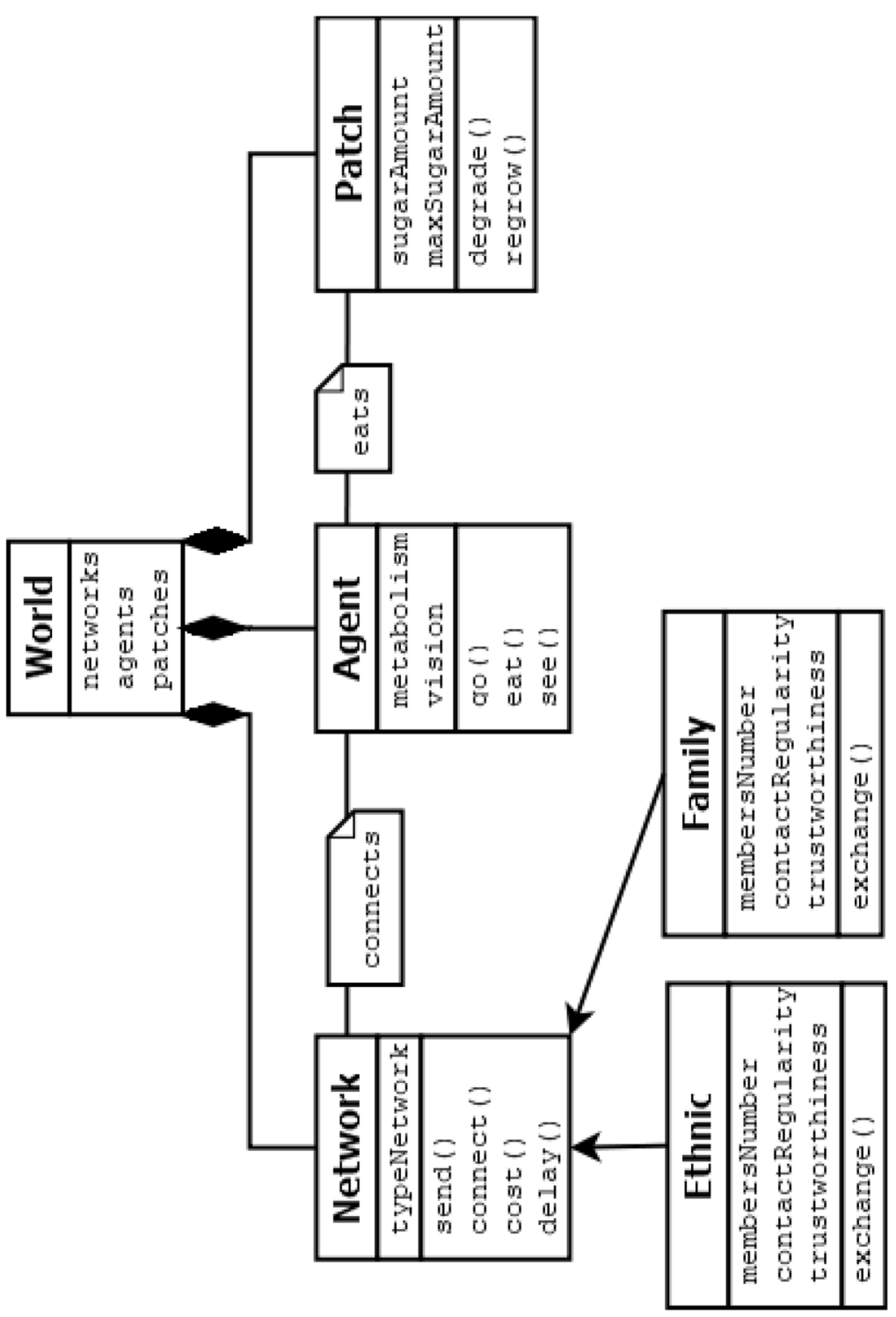

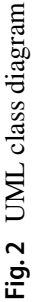


will only undergo movement if it finds a patch that affords a better opportunity to harvest sugar, despite the costs and risks involved in getting there.

In keeping with the concept of South-South mobility, where borders are less important than other processes governing mobility, movement across the field is equally costly in all directions, so that no artificial borders are imposed (only the natural border presented by the resource-poor area between the two hills), and the only impediments to the movement of agents are the costs and risks. Furthermore, mobility induces energetic costs proportional to the travel distance [45]. Also, the further away the travel destination, the more incomplete the knowledge and the more unreliable the gathered information about the place which introduces an element of risk to mobility [78]. We assume that the risks are equal to or smaller than the mobility costs. The costs are estimated by the travel distance times the mobility-cost factor, which is a user-defined parameter. The risks are probabilistic phenomena that can incur further costs. Thus, they are estimated by the travel distance times, a random factor between zero and the mobility-cost factor [45, 78].

\section{Networks}

Moreover, networks are introduced, which influence the agent's decision to move. Agents can build networks with other agents via links. Based on the theoretical background, we implement family networks and ethnic networks. Out of the perspective of each agent, all agents that are within the radius of the vision of the respective agent belong to the family network. These networks stand for the emotionally close kinship-based groups within which pastoralists predominantly share information, and this closeness is here represented by the initial spatial proximity. The ethnic networks in turn, depend upon weaker ties. The cell grid is diagonally divided into two halves. All agents on the same half belong to the same ethnicity and make up an ethnic network. This 50:50 is an arbitrary assumption and it could be any other mix, but we decided the 50:50 for the sake of simplicity. We assume that agents always tell the truth and the model could be extended by changing this point [73], but it has not been the focus so far.

These networks form a medium of information exchange between agents. Since, in this model, vision is a crucial element of mobility, acting as a limiting factor on how agents can move, the information possessed by an agent is represented by the area that they can "see". Thus, the patches within one's vision carry with them all the information about the pasture quality, weather conditions and possible market opportunities. Consequently, agents share these areas with other agents that are connected to them in their networks, providing, as a bundle, all of this information. Therefore, being well-integrated in networks grants agents more opportunities to migrate. See Fig. 3 for a sequencing diagram summarizing the process in UML [9]. 


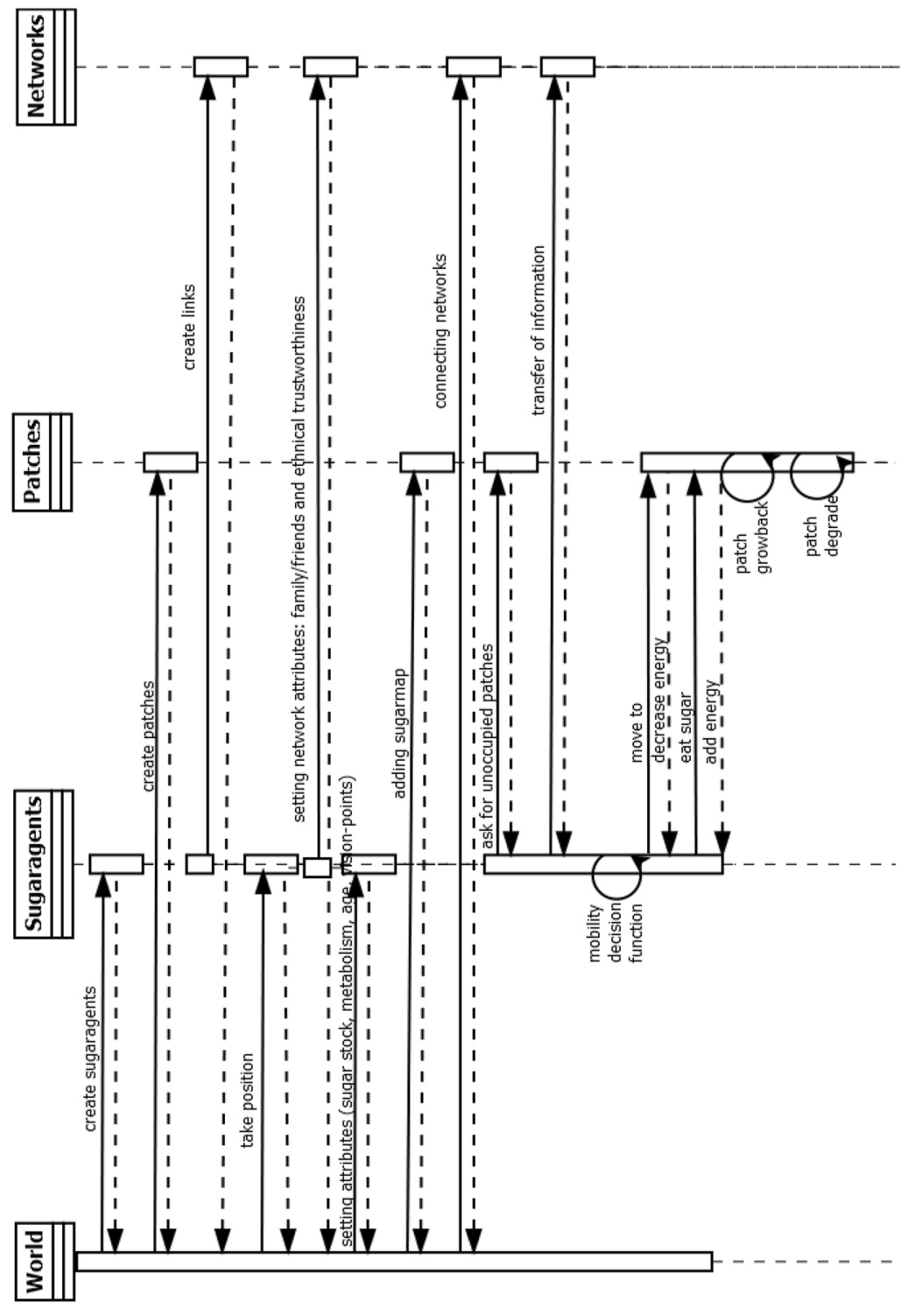

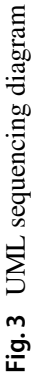




\section{Simulated scenarios}

\section{Social dimension}

The network attributes that depend upon the kind of network make up the social dimension of the model. The first such attribute is emotional "closeness". Family networks are taken to be emotionally closer than ethnic networks. Thus, agents trust their family members the most. This is implemented via a probability of $90 \%$ that agents trust the information they receive from their family networks. Agents trust their ethnic fellows with only $30 \%$ probability. The reason why we choose these percentages is based on a combination of pragmatism and plausibility. In this case, pragmatism is related to the possibility of constructing a sensitivity analysis incrementing the value of the variable and decreasing it as a control mechanism. Plausibility is based on the documented fact of a greater trust within the family than with ethnic ties [13, 28].

The second attribute "contact regularity" also depends on the kind of network. Since agents get in touch with their family more often, the contact regularity is higher for this case. They update the information in their family network with every tick. In their ethnic network, agents update the information with every third tick.

\section{Technological dimension}

The technological dimension is a factor of the point in time that the model represents. It encompasses the attributes "cost of communication" and "time delay". Both attributes are the same for all agents, but vary for the different runs of the model. This represents different points in time, from eras when letter communication was predominant until today when communication happens via smartphones. On one hand, the cost of communication represents those expenditures that are likely to be captured in a monetary form. On the other hand, time delay is here representing the technological barriers that are present during the exchange of information and that can hardly be overcome with a greater expenditure of money.

For instance, cost of communication was significantly higher in times of letter communication than today. Therefore, a higher technological dimension is represented by lowered costs of communication in the model. The agents have to be able to afford the costs of communication to exchange information.

"Time delay" represents the length of time until agents can update their information. Receiving an answer via overseas letters takes significantly longer than via instant messaging services (e.g., Whatsapp) or social media. In addition, the information in the letter is from the point in time when the sender wrote the letter and not simultaneous with the receipt of the letter. This means that the information the agents receive is not simultaneous but as old as the time delay. Therefore, a higher time delay results in agents receiving, and acting on, outdated information. This attribute is also the same for all agents, but varies for different runs. In the literature about pastoralist communities, networks buffer risk and cost effects of communication, but are not capable of entirely diminishing it $[56,76]$. 


\section{Description of scenarios}

Scenario 1: social low-technological high (ethnic ties with new technology) The first scenario combines agents with poor social relation having access to new technologies. "Social low" (representing the social dimension being set to low) is implemented by agents relying only on ethnic bonds, which corresponds to low trustworthiness and low contact regularity. "Technological high" brings the advances of zero cost for communication and zero time delay in the reception of information.

Scenario 2: social high-technological high (close family ties and new technology) The second scenario depicts a situation with family networks and new technologies. "Social high" depicts agents having family networks which feature high trustworthiness and high contact regularity. "Technological high" is described above.

Scenario 3: social low-technological low (random ethnic ties) The third scenario represents a situation of agents being neither technologically nor socially well connected. "Social low" is implemented as described above and "technological low" represents agents being obliged to pay for communication and receiving information only with a time delay.

Scenario 4: social high-technological low (close family ties) This scenario introduces socially well-connected agents relying on old technologies. "Technological low" is implemented as above.

Scenarios 5-12: altering the ideal types of the first four scenarios To complement the first analysis of the four ideal types that allows us to compare plausible scenarios, we changed the specific combinations of parameters to identify the individual contribution of the different parameters. ${ }^{1}$ Opening the social dimension (changing trust and contact regularity) shows the most interesting results presented in Fig. 4. Opening the scheme of the ideal types, we created 8 scenarios for the social dimension, which we labeled according to the first scheme of Table 1 (low social dimension=only ethnic bonds communicate, high social dimension=all bonds communicate; low trust $=30 \%$, high trust $=85 \%$; low contact regularity $=$ every 3 ticks, high regularity = every tick) for Fig. 4.

A similar analysis was carried out on the technological dimension. The results are as expected (high communication costs prevent mobility). Because our focus is on the social sciences, these latter results were placed in the Appendix of this article.

\section{Additional parameters}

Since mobility is not clearly defined, several measures are possible. For a comprehensive analysis, it is reasonable to compare the different measures:

\footnotetext{
1 The authors thank one of the reviewers for this idea.
} 


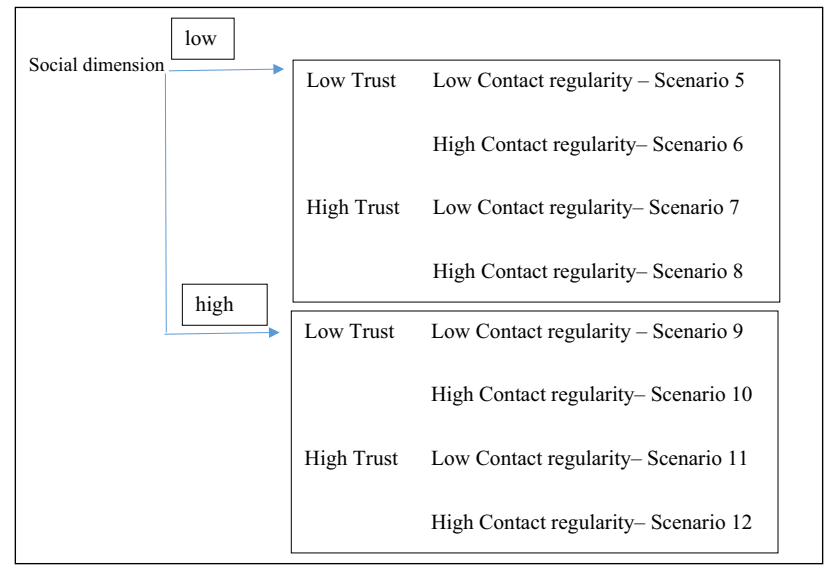

Fig. 4 Opening the social dimension

\section{Mobility as final distance traveled}

This is a geographically based definition of mobility. It counts the distance between the starting point of an agent and the final point when the run stops. Mobility is then defined as the average over the distances agents traveled.

\section{Mobility as number of agents moved to the other hill}

This definition stems from discussions about individuals having to cross a natural or man-made border in the course of moving. This border is represented by the region between the sugar hills which offers only very few resources. Thus, the definition encompasses the number of agents that moved from their original sugar hill to the other one, thus possessing the resources or the network connections enabling them to cross this barrier.

\section{Mobility as sum over all distance moved}

This definition has its background in current academic discussions on mobility as a comprehensive topic including various kinds of mobility [34]. Thus, all distances agents ever moved are counted and averaged. This differs from the geographically based definition of traveling agents that return to their original position will be counted as having moved a nonzero distance. 


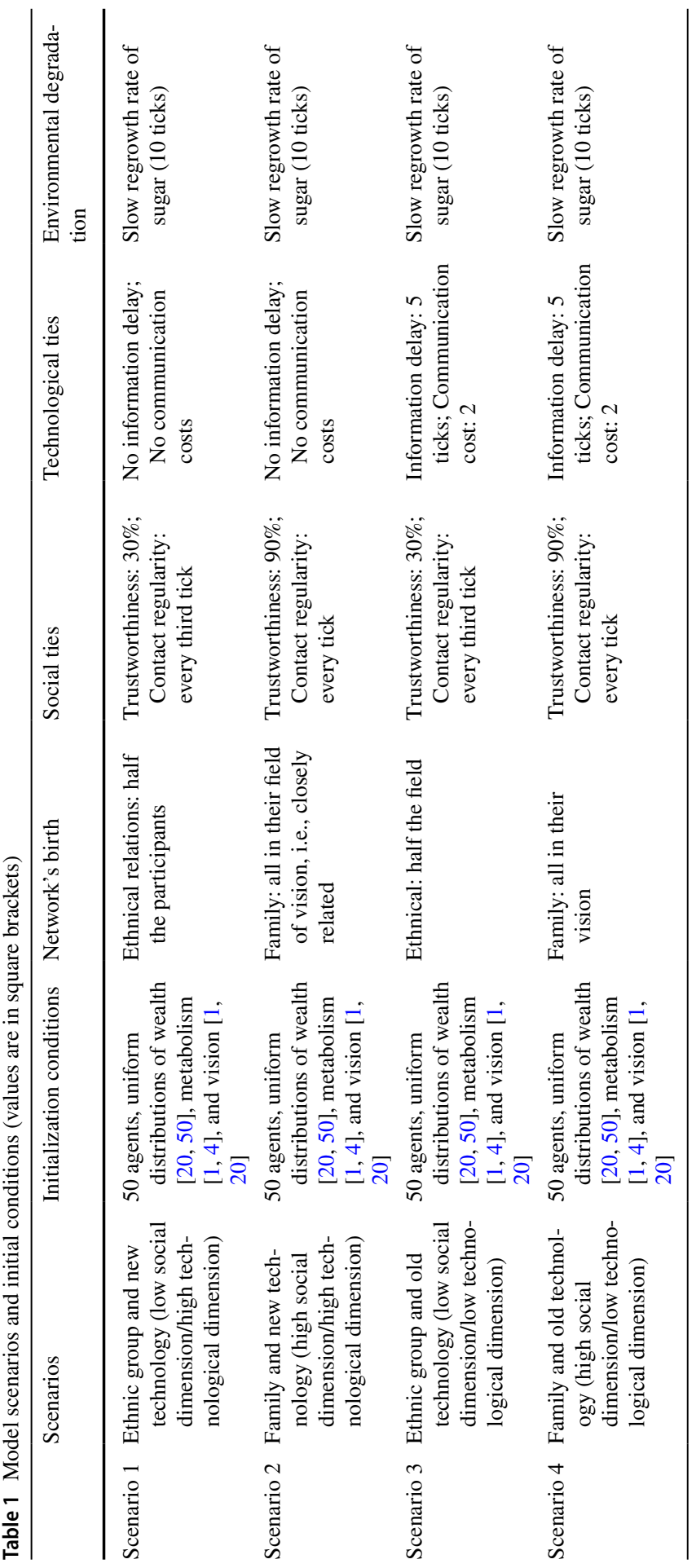



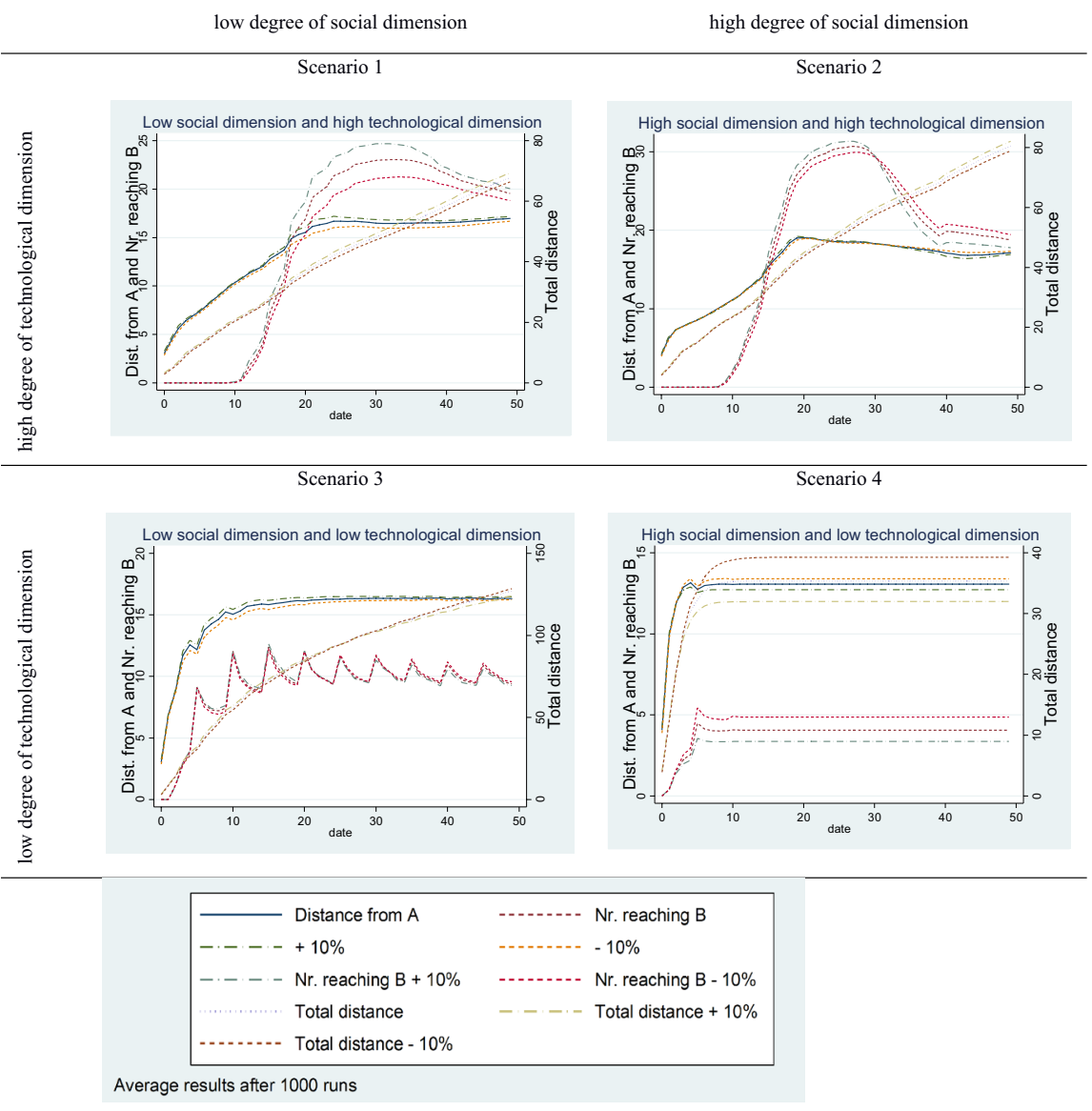

Fig. 5 Sensitivity of mean results with Delta $=10 \%$ (1000 simulations)

\section{Results}

Table 1 shows the four different scenarios of the adapted Sugarscape model defined according to the initial conditions used to vary the model. The first column typologizes the different scenarios based on how the network was originally settled and the social and technological relations behind it (social and technological ties in high and low dimensions). The other components, namely the initialization conditions and environmental degradation, complement the model specification and its initialization.

The results were generated with Netlogo 6.0.4 and show three different versions of mobility in Fig. 5 (final distance, agents moved to the other hill, and sum of distance moved). The $\mathrm{X}$-axis remains constant (date) throughout the four scenarios, with time characterized in the form of ticks (see Fig. 5). The ticks are a fictitious unit that represent the completion of one cycle of the entire program. It could be a 
day, a week, or another measure of time. There are two different graph measures for the Y-axis. The Y-axis located on the left of the diagram shows the final distance and agents moved to the other hill and the scale located on the right corresponds to the sum of distances moved for each scenario, respectively.

\section{Scenario 1: social low-technological high (ethnic group and new technology)}

The first scenario combines agents that are poorly related socially but with access to new technologies. Both "social low" and "technological high" are implemented as described in Table 1. This scenario demonstrates how, over time, mobility in its three forms in almost all the cases increases. This increase occurs in a non-linear way allowing almost half of the individuals in the experiment to reach Sugarscape B. The form of mobility shows a non-linearity in the three definitions of mobility. While the agents begin to move very quickly (noticed in the exponential increase of the two distance measurements) until after 10 ticks, agents remain in Sugarscape A. From there, the discovery effect happens and is transported through special technological networks. This produces the rapid increase of agents changing from A to B. The number of agents reaching Sugarscape B demonstrates this. Finally, the series stabilizes after some agents (two agents on average) return to Sugarscape A, reaching a balance between the available resources and the number of agents stabilizing with around 20 agents in Sugarscape B.

\section{Scenario 2: social high—-technological high (family and new technology)}

The second scenario depicts a situation with family networks and new technologies. The effect of the interaction of both social and technological networks produces an increase in (almost continuous) mobility in the variants studied during the time. This increase also occurs in a non-linear way where more than half of the individuals in the experiment reach Sugarscape B. A similar non-linearity is maintained in the three definitions of mobility that provide the shape of movement of agents through the artificial world. While the agents begin to move in a fast manner (noticed in the exponential increase of distance measurement from point A) up to and before nine ticks, no agent reaches Sugarscape B. From there, a stronger discovery is produced than in the previous scenario. This rapid increase of agents from A to B is demonstrated in the number of agents reaching Sugarscape B. It should also be noted that the series does not stabilize once the agents reach the maximum in Sugarscape B due to a return effect. Approximately $30 \%$ of those who reached B return to their place of origin (Sugarscape A) to stabilize at a point similar to the previous scenario (around 20 agents). 


\section{Scenario 3: social low-technological low (random ethnic ties)}

The third scenario represents a situation where agents are neither technologically nor socially well connected. This scenario presents a more stable result in stages than the first two scenarios, demonstrating the actors' increase in mobility. It is interesting that during the first stage, what we have described as discovery occurs almost from the beginning of the experiment. After reaching a peak of mobility, some actors become seasonal migrants, reaching point B and returning to point A where they began their mobility. In this seasonal variation of the number of actors reaching point $\mathrm{B}$, we can observe a mechanism toward stabilization as the peak and return of actors decreases.

\section{Scenario 4: social high technological low (closeness family times)}

The last scenario shows a very special result, as it starts in the same way as previously with a discovery phase, and quickly reaches stability. The reason for this behavior can be found in the strong importance of family networks and the weak effect of technological networks.

A sensitivity analysis was carried out in which different parameters were tested with changes between $\pm 5 \%$ and $\pm 10 \%$; however, we only present the $\pm 10 \%$ results for the sake of clarity, because the results with $\pm 5 \%$ did not add new information. From these variations in the initial conditions of the model, behavior over time is generally stable and does not affect the behavior of the model (see Fig. 5). This shows a certain robustness of the results where the initial conditions of the networks do not incidentally affect the behavior of the model, but rather reveal a systematic method to explain certain phenomena from the literature on the mobility of agents.

An important point to note is that, in the scenario 1 model, the average series of the sensitivity analysis intersects with the mean effect. This gives the pattern a counter stream effect, which is even greater with higher initial conditions. This effect is considered within the discussion of the results.

Opening the four ideal types of the social dimension, the results show that the change from low to high contact regularity alters the shape of the curves, making them more continuous, i.e., with less breaks. In addition, the change from low to high trust makes the phenomenon of stream and counter stream analyzed here even stronger. Finally, altering the social dimension from low to high also affects the strength of stream and contrast, but only minimally (Fig. 6).

\section{Discussion}

\section{Results and methodological approach}

In the literature on migration, social networks play an important role [52, 55, 68]. However, most migration researchers (mostly residents in the Global North) adopt 


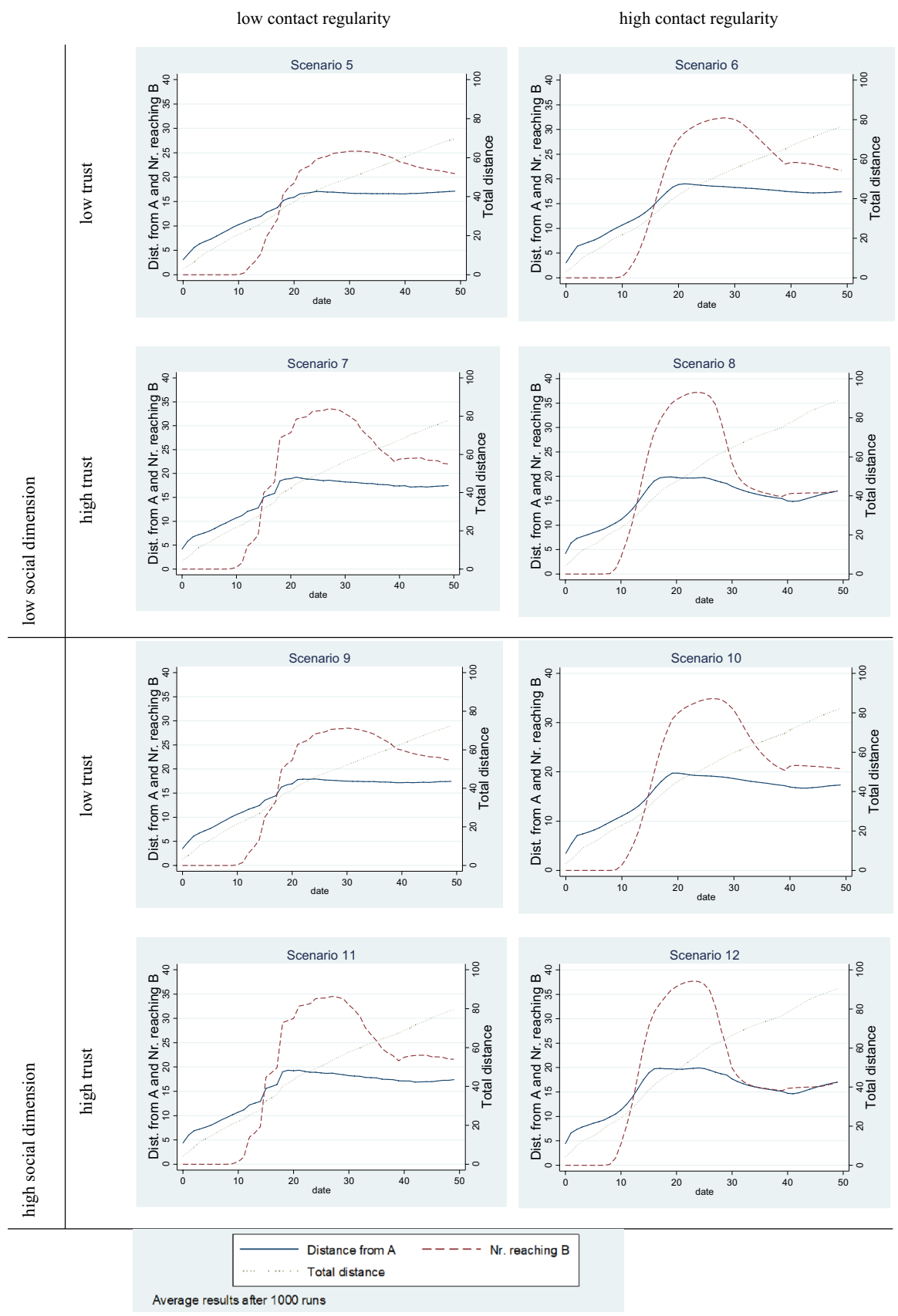

Fig. 6 Variations of scenarios (low and high social dimension with high and low trust and low and high contact regularity) 
the more or less hidden assumption that migration occurs from the Global South to the Global North [58, 59] based on the traditional drivers of migration [54] such as the diversity of regions, the degree of difficulty, and economic fluctuations [49]. This fact has had an effect on migration theories and on the political view of migration flows, and migration research has aimed as an objective to control this flow from the Global South to the Global North, presenting it as humanitarian assistance, economic and social threat, opportunity, or security risk according to different historical and political contexts [15]. The interpersonal ties have different characteristics, and the network characteristics have the capacity to influence individual action and collective behavior. In this research, we start using several typologies of networks in families (scenarios 1-4), as an example of nearby groups, and more diverse groups who join via special ethnic linkages in our implementation, but they could be religious social constructions, for example. To extend this analysis, we opened the ideal types (scenarios 1-4) and generated hybrid scenarios by moving only one parameter (scenarios 5-16). The results correlate in accordance with the literature, as the greater the strength of the interpersonal relationship, the greater the mobility in a general form, as proposed by supposition 1. This result was expected and acquires another degree of significance when we observe not only the increase in mobility, but also the way in which this increase happens.

In addition, other forms of social networks are possible, including those based on different forms of communication [22, 61], particularly as communication through the internet affects our lives, the way we interact, and how mobility occurs [2]. Our results show increased mobility as the technological networks allow a cheaper and faster connection (supposition 2). This quantitative analysis of the relationship between mobility and technology in social networks complements and extends the qualitative analysis carried out by various authors [21,54]. An interesting point that emerges from scenarios 5 to 16 is that the relationship with the intensity of the contact, less or more contact, does not affect the final form of the mobility (stream and counter stream), but its intensity and continuity. The high cost of communication can be reduced to the point where mobility is no longer possible.

The current research presents this connection of social networks and technology as an additional form of mobility and a resilience strategy within the literature about a community of pastoralists. According to the main supposition, the connection of social and technological networks and their simultaneous interconnection allows us to observe, in general terms, how the greater the connection of networks, the greater the tendency to mobilize. This result is not surprising, as other authors have reached the same conclusion in other contexts [53, 54].

Mobility is a primary factor in survival [20]. However, these forms of connection through social networks with different configurations (families and ethnic groups) and technologies complement the work already completed in terms of survival strategies, such as diversifying risk with social networks [32, 62, 68].

The results regarding the increment's form of mobility are the most surprising. From these findings, we gain substantial knowledge about this particular model, as the experiments carried out by Epstein and Axtell [26] show the actors' tendencies to hibernate when they are confronted with environmental degradation. The presented research shows that the first move in mobility takes time, but then, the 
individuals recover and surpass their capacities on the discovered terrain, later returning and stabilizing the population between the area of emission and arrival. We have analyzed this process as (1) wait, (2) discovery, (3) return, and (4) stabilization. It is a process known in migration theory as stream and counter stream [49], where agents tend to follow known routes and, after starting to mobilize, the reasons for mobility disappear because of too many new arrivals. Following a reevaluation, finally, a counter stream occurs. The current model allows us to observe this counter stream, which is no longer associated with knowledge of the route, but instead with the strength of interpersonal ties and the technology used within the social network.

An important question is why agents start migrating later when networks are stronger. This is a well-working result of south-south mobility and the migration theory, because the research question becomes why people do not move as a form of paradox of staying [41], when the theory indicates that they should migrate. This research about Sugarscape found the same reasons associated with the paradox of staying $[41,74]$ in the same place and with strong forces of mobility as the literature: the attraction of contact groups, such as family and other interpersonal ties, is greater than the attraction capacity of better resources. Moreover, the strength of technology convinces them, at least in the beginning, and it is advantageous to stay, because it is familiar and has worked well for them thus far.

\section{Advantages, disadvantages, and future orientation of the research}

The objective of this study is to demonstrate the ability of agent-based modeling to analyze the phenomenon of mobility and migration when other quantitative research techniques fail. Modeling, in general, is a research methodology that has advantages when analyzing the situations related to mobility and migration presented in this study. It allows us to explore, without having to predict, situations that are plausible, but do not exist $[24,25]$. The example used in this study is a world of ethnic tribes that can relate through instant social networks reminiscent of Twitter and Facebook. This approach also demonstrates the capacity to analyze phenomena that are difficult to observe and document empirically, as in the case of mobility and migration $[1,48]$. The ability to run the model thousands of times with slightly different initial conditions and generate databases to analyze social phenomena such as migration and mobility makes this a promising tool for various fields of study. Finally, the agent-centered approach was of interest because of its capacity to introduce complex networks produced endogenously through direct contact with agents that adapt their behavior, producing results such as the non-linear movement behaviors shown in our model.

As it is not possible to make an exhaustive list of all the limitations of this approach, a list of the most important limitations of the model was created with possible courses of action for future research. The most significant limitation is based on the simplicity of the decision of the agents to mobilize. More complexity was added to the original model to achieve a qualitative improvement of this point. However, this decision includes other dimensions as for example the social and cultural embeddedness $[41,74]$, the role within a family, prestige, expected future income or 
differences in risk propensity that have not been incorporated as the greatest effort was expended to create and analyze different types of networks.

There are other types of networks playing a strong role when it comes to mobility and migration, which do not fall within the studied categories of families and ethnic groups. For example, one factor in networks is the creation of companies as social structures through an innovation, known as a discovery, or patent. These networks in forms of companies that arise spontaneously have not been examined in this study and can surely bring a new perspective to the research of migration. The networks analyzed were based on the traditional forms studied within the migration literature.

The characteristics of the agents were put aside in this study as analysis of the networks was the priority. Analysis of the agents that decide to mobilize could be based on one of the classic questions in migration literature, what are the characteristics of the people who decide to mobilize. This, in combination with other methodological approaches of the quantitative analysis of social network data, and qualitative research is a promising approach to continue extending the relevance of ABM.

\section{Conclusion}

This study provides a detailed analysis of the effect of social and technological networks on the decision of a given population to move and migrate from one point to another in an artificial world with freedom to move and facing environmental degradation. The analysis implies that the effect of both networks increases mobility under these circumstances. A total effect of increased migration can be observed along the supposition that the greater the connection, the greater the effect. This is well in line with previous research results finding that social networks diversify the risks of mobility. Networks facilitate mobility that can act as an adaptation strategy to environmental degradation and increase resilience. Especially, the impact of new technologies facilitates mobility as shown in our results, which puts an emphasis on the utility of cellular phones in a pastoralism context.

The most interesting result is not the increase itself, but the way this increase occurs. In this investigation, the agents were in one of two zones that concentrate resources, leaving the other zone to be discovered by the agents. This is unlike the original Sugarscape model where the actors are distributed throughout the artificial world. It was discovered through this research that the differences between the networks cause a certain series of phases that can be summarized as (1) wait, (2) discovery, (3) return, and (4) stabilization. Interestingly, the strength of the networks not only causes increased mobility, but also generates an increase in the speed and strength in which these four effects occur, resulting in a similar approximate balance. The faster and stronger the effect, the greater the return effect. This is known in the literature of migration as stream and counter stream effect.

This research contributes primarily with its inter-disciplinary approach to connect networks, pastoralism, and agent-based modeling and thereby possible analysis of the effects of different networks on the agents' mobility in a herder's context. The results could influence at least three clusters of scientific literature. The first and most direct is the literature on social and technological networks. The results presented here extend 
the knowledge regarding the positive effect of social and technological networks and their non-linear character on decisions of mobility and migration, especially in a pastoralism context. The second field is agent-based modeling in general, and the literature on the Sugarscape model in particular. It demonstrates how to move forward with an artificial world through an unplanned extension of the original model. The questions left open by Epstein and Axtell [26] regarding the effect of environmental degradation on agents was expanded to overcome the initial immobility and show mobilization as adaptation instead. The third possible field of literature is the simulation of ancient worlds [29], and more specifically hunter-gatherer societies [5, 6]. There may be situations in which this model could be adapted with minor changes to a specific geographic location in the past.

\section{Appendix}

This appendix details here the second set of results with the technological dimension (communication cost and response delay) broken down as the scenarios 5-12 are presented. This results in four scenarios, labeled as follows: low communication cost $=0$ sugar, high communication $\operatorname{cost}=2$ resources units, low response delay $=1$ tick, and high response delay $=5$ ticks. See Fig. 7 .

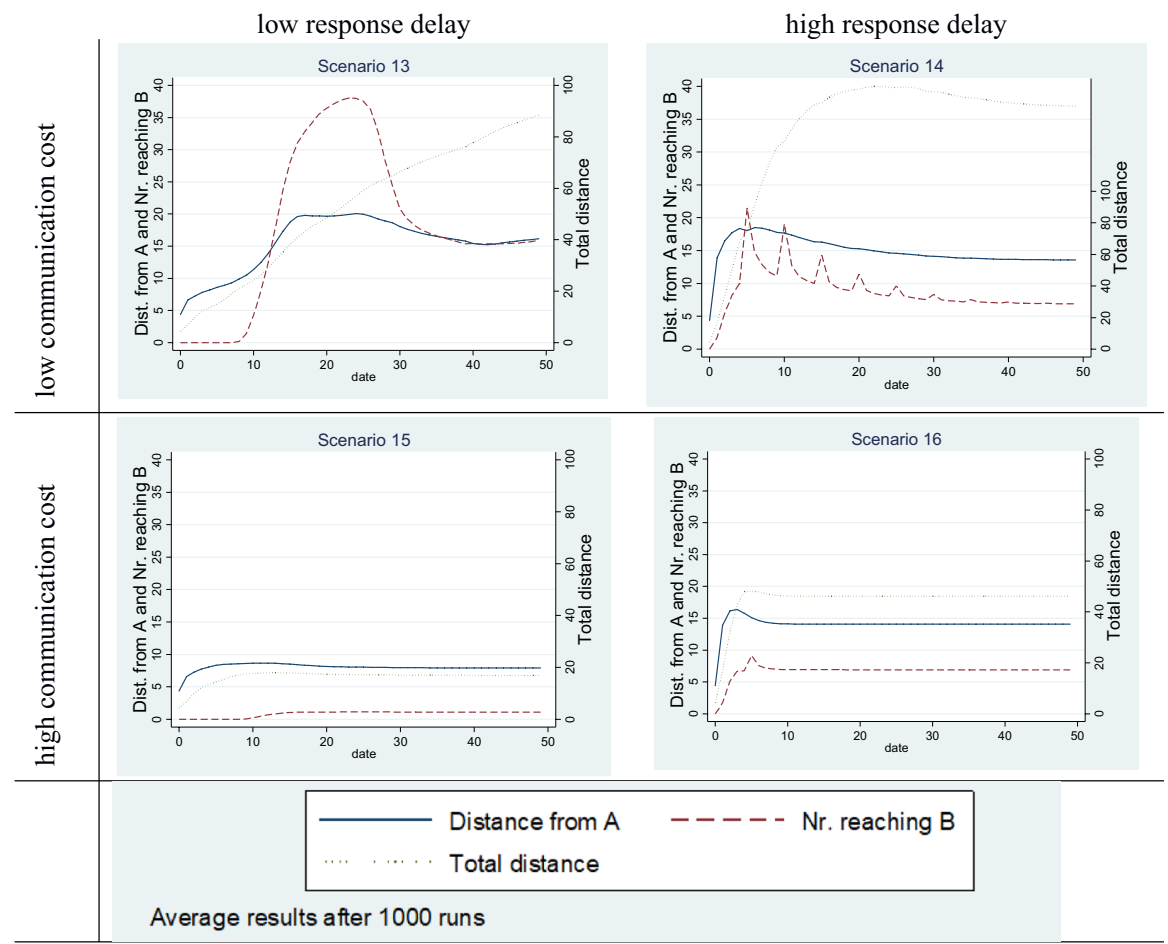

Fig. 7 Variations of scenarios (low and high communication cost with low and high response delay) 
Supplementary Information The online version contains supplementary material available at https://doi. org/10.1007/s42001-020-00100-w.

Acknowledgments We would like to thank Dr. Christiane Fröhlich for the advice about the migration literature, and the external reviewers for their helpful comments.

Author contributions All authors contributed to the study conception and design. Material preparation, data collection, and analysis were performed by SS, JMRL, and MS. The first draft of the manuscript was written by JMRL and MS, and edited by Jürgen Scheffran who also provided ideas for the model. All authors commented on previous versions of the manuscript. All authors read and approved the final manuscript.

Funding Open Access funding enabled and organized by Projekt DEAL.. This research was partly supported by the CLICCS Cluster of Excellence funded by the German Research Foundation.

Data availability Model and data are included in this submission. Results from our simulation experiments are going to be publicly available and can be downloaded along with the NetLogo model (as code in the Netlogo file was not supported by the upload webpage) and Stata-code and database are available to this first submission upon request (csv format was not supported by the upload system).

Code availability The NetLogo model and the Stata-code and files for reproducibility of analysis are going to be available at CoMSES model library and are enclosed to this publication as text for the model code.

\section{Compliance with ethical standards}

Conflict of interest The authors declared no potential conflicts of interest with respect to the research, authorship, and/or publication of this article.

Open Access This article is licensed under a Creative Commons Attribution 4.0 International License, which permits use, sharing, adaptation, distribution and reproduction in any medium or format, as long as you give appropriate credit to the original author(s) and the source, provide a link to the Creative Commons licence, and indicate if changes were made. The images or other third party material in this article are included in the article's Creative Commons licence, unless indicated otherwise in a credit line to the material. If material is not included in the article's Creative Commons licence and your intended use is not permitted by statutory regulation or exceeds the permitted use, you will need to obtain permission directly from the copyright holder. To view a copy of this licence, visit http://creativecommons.org/licen ses/by/4.0/.

\section{References}

1. Abel, G. J., \& Sander, N. (2014). Quantifying global international migration flows. Science, $343(6178), 1520-1522$.

2. Alonso, A., \& Oiarzabal, P. J. (2010). Diasporas in the new media age. Identity, politics, and community. Nevada: University of Nevada Press.

3. Alvarez-Galvez, J. (2016). Network models of minority opinion spreading. Social Science Computer Review, 34(5), 567-581.

4. Bankes, S., Lempert, R., \& Popper, S. (2002). Making computational social science effective. Social Science Computer Review, 20(4), 377-388.

5. Barceló, J. A., Bernal, F. D. C., Olmo, R. D., Mameli, L., Quesada, F. J. M., Poza, D., et al. (2014). Social interaction in hunter-gatherer societies. Social Science Computer Review, 32(3), 417-436.

6. Barceló, J. A., \& Del Castillo, F. (2016). Simulating prehistoric and ancient worlds. Cham: Springer International Publishing. 
7. Barth, F. (1961). Nomads of South Persia: the Basseri tribe of the Khamseh Confederacy. Oslo: Oslo University Press.

8. Bendor, T. K., \& Scheffran, J. (2018). Agent-based modeling of environmental conflict and cooperation. Boca Raton: Taylor \& Francis.

9. Bersini, H. (2012). UML for ABM. Journal of Artificial Societies and Social Simulation. https://doi. org/10.18564/jasss.1897.

10. Billari, F. C., Fent, T., Prskawetz, A., \& Scheffran, J. (2006). Agent-based computational modelling: applications in demography, social, economic and environmental sciences. Heidelberg: PhysicaVerlag Heidelberg.

11. Bonabeau, E. (2002). Agent-based modeling: Methods and techniques for simulating human systems. Proceedings of the National Academy of Sciences, 99(3), 7280-7287.

12. Borge-Holthoefer, J., Piedrahita, P., \& Arenas, A. (2018). Evolving activity cascades on socio-technological networks. Journal of Computational Social Science, 1(1), 67-79.

13. Boyd, M. (1989). Family and personal networks in international migration: recent developments and new agendas. The International Migration Review, 23(3), 638-670.

14. Butt, B. (2015). Herding by mobile phone: technology, social networks and the "Transformation" of Pastoral Herding in East Africa. Human Ecology, 43(1), 1-14.

15. Chimmi, B. S. (1998). The geopolitics of refugee studies: a view from the South. Journal of Refugee Studies, 11(4), 350-374.

16. Choi, H. J. (2014). How ethnic exclusion influences rebellion and leader survival. Social Science Computer Review, 32(4), 453-473.

17. Christiansen, J. H., \& Altaweel, M. (2006). Simulation of natural and social process interactions. Social Science Computer Review, 24(2), 209-226.

18. Cioffi-Revilla, C. (2010). A methodology for complex social simulations. Journal of Artificial Societies and Social Simulation. https://doi.org/10.18564/jasss.1528.

19. Cioroianu, I. (2020). An agent-based model of cooperation with cross-cutting identity dimensions. Journal of Computational Social Science. https://doi.org/10.1007/s42001-020-00065-w.

20. Debsu, D. N., Little, P. D., Tiki, W., Guagliardo, S. A. J., \& Kitron, U. (2016). Mobile phones for mobile people: the role of information and communication technology (ICT) among livestock traders and borana pastoralists of Southern Ethiopia. Nomadic Peoples, 20(1), 35-61.

21. Dekker, R., \& Engbersen, G. (2014). How social media transform migrant networks and facilitate migration. Global Networks, 14(4), 401-418.

22. Dekker, R., Engbersen, G., \& Faber, M. (2016). The Use of Online Media in Migration Networks. Population, Space and Place, 22(6), 539-551.

23. Dressler, G., Mueller, B., \& Frank, K. (2012). Mobility a panacea for pastoralism? An ecological-economic modelling approach. International Environmental Modelling and Software Society (iEMSs). https://scholarsarchive.byu.edu/iemssconference/2012/Stream-B/47. Accessed 15 May 2020.

24. Epstein, J. M. (2008). Why model? Journal of Artificial Societies and Social Simulation, 11, 12.

25. Epstein, J. M. (2009). Modelling to contain pandemics. Nature, 460(7256), 687.

26. Epstein, J. M., \& Axtell, R. (1996). Growing artificial societies: social science from the bottom up. Washington: Brookings Institution Press.

27. Faist, T. (1995). Sociological theories of international south to north migration: the missing meso-link. Working papers of the Centre for Social Policy Research, p. 17.

28. Fawcett, J. T. (1989). Networks, linkages, and migration systems. International Migration Review, 23(3), 671-680.

29. Frantz, C., Purvis, M. K., \& Nowostawski, M. (2014). Agent-based modeling of information transmission in early historic trading. Social Science Computer Review, 32(3), 393-416.

30. Freier, K. P., Bruggemann, R., Scheffran, J., Finckh, M., \& Schneider, U. A. (2012). Assessing the predictability of future livelihood strategies of pastoralists in semi-arid Morocco under climate change. Technological Forecasting and Social Change, 79(2), 371-382.

31. Galvin, K. A. (2009). Transitions: pastoralists living with change. Annual Review of Anthropology, 38, 185-198. 
32. Gamble, C. (1983). Culture and society in the Upper Paleolithic of Europe. In A. R. Bailey (Ed.), Hunter-gatherer economy in prehistory: a European perspective (pp. 201-211). Cambridge: Cambridge University Press.

33. Gilbert, N. (2008). Agent-based models. Thousand Oaks: Sage Publications.

34. Gioli, G., Hugo, G., Costa, M. M., \& Scheffran, J. (2016). Human mobility, climate adaptation, and development. Migration and Development, 5(2), 165-170.

35. Glick Schiller, N., \& Salazar, N. B. (2013). Regimes of mobility across the globe. Journal of Ethnic and Migration Studies, 39(2), 183-200.

36. Granovetter, M. S. (1973). The strength of weak ties. American Journal of Sociology, 78(6), 1360-1380.

37. Gurak, D. T., \& Caces, F. (1992). Migration networks and the shaping of migration systems. In M. M. Kritz, L. L. Lim, \& H. Zlotnik (Eds.), International migration systems: a global approach (pp. 150-176). Oxford: Clarendon Press.

38. Hailegiorgis, A., Crooks, A., \& Cioffi-Revilla, C. (2018). An agent-based model of rural households' adaptation to climate change. Journal of Artificial Societies and Social Simulation. https:// doi.org/10.18564/jasss.3812.

39. Hailegiorgis, A. B., Kennedy, W. G., \& Rouleau, M. (2010). An agent based model of climate change and conflict among pastoralists in East Africa. International Congress on Environmental Modelling and Software. https://scholarsarchive.byu.edu/iemssconference/2010/all/69. Accessed 01 June 2019

40. Hannam, K., Sheller, M., \& Urry, J. (2006). Mobilities, immobilities and moorings. Mobilities, 1(1), 1-22.

41. Hjälm, A. (2014). The 'Stayers': dynamics of lifelong sedentary behaviour in an urban context. Population, Space and Place, 20(6), 569-580.

42. Jean-Richard, V., Crump, L., Moto Daugla, D., Hattendorf, J., Schelling, E., \& Zinsstag, J. (2014). The use of mobile phones for demographic surveillance of mobile pastoralists and their animals in Chad: proof of principle. Global Health Action, 7(1), 23209.

43. Johnson, P. E. (2002). Agent-based modeling: what I learned from the artificial stock market. Social Science Computer Review, 20(2), 174-186.

44. Joseph, K., Morgan, G. P., Martin, M. K., \& Carley, K. M. (2014). On the coevolution of stereotype, culture, and social relationships. Social Science Computer Review, 32(3), 295-311.

45. Kelly, R. L. (1992). Mobility/sedentism: concepts, archaeological measures, and effects. Annual Review of Anthropology, 21(1), 43-66.

46. Klabunde, A., \& Willekens, F. (2016). Decision-making in agent-based models of migration: state of the art and challenges. European Journal of Population, 32(1), 73-97.

47. Komito, L. (2011). Social media and migration: virtual community 2.0. Journal of the Association for Information Science and Technology, 62(6), 1075-1086.

48. Koser, K. (2009). Dimensions and dynamics of irregular migration. Population, Space and Place, 44(4), 181-193.

49. Lee, E. S. (1966). A theory of migration. Demography, 3(1), 47-57.

50. Lerman, K., Marin, L. G., Arora, M., de Lima, L. H. C., Ferrara, E., \& Garcia, D. (2018). Language, demographics, emotions, and the structure of online social networks. Journal of Computational Social Science, 1(1), 209-225.

51. Madianou, M., \& Miller, D. (2013). Migration and new media: transnational families and polymedia. Abingdon: Routledge.

52. Massey, D. S. (1988). Economic development and international migration in comparative perspective. The Population and Development Review, 14, 383-413.

53. Massey, D. S., Alarcón, R., Durand, J., \& González, H. (1990). Return to Aztlan: the social process of international migration from Western Mexico. Berkeley: University of California Press.

54. Massey, D. S., Arango, J., Hugo, G., Kouaouci, A., Pellegrino, A., \& Taylor, J. E. (1993). Theories of international migration: a review and appraisal. The Population and Development Review, 19, 431-466.

55. Massey, D. S., Arango, J., Hugo, G., Kouaouci, A., Pellegrino, A., \& Taylor, J. E. (1994). An evaluation of international migration theory: the North American case. The Population and Development Review, 20, 699-751. 
56. McAllister, R. R., Gordon, I.J., \& Stokes, C.J. (2005). KinModel: sks. International Congress on Modelling and Simulation, pp. 170-176.

57. Moritz, M., Hamilton, I. M., Yoak, A. J., Scholte, P., Cronley, J., Maddock, P., et al. (2015). Simple movement rules result in ideal free distribution of mobile pastoralists. Ecological Modelling, $305,54-63$.

58. Nawyn, S. J. (2016). Migration in the global south: exploring new theoretical territory. International Journal of Sociology, 46(2), 81-84.

59. Nawyn, S. J. (2016). New directions for research on migration in the global south. International Journal of Sociology, 46(3), 163-168.

60. Neely, C., Bunning, S., \& Wilkes, A. (2009). Review of evidence on drylands pastoral systems and climate change. Rome: FAO. http://www.fao.org/fileadmin/user_upload/rome2007/docs/ Drylands_pastoral_systems_and_climate\%20change.pdf. Accessed May 2020.

61. Oiarzabal, P. J., \& Reips, U.-D. (2012). Migration and diaspora in the age of information and communication technologies. Journal of Ethnic and Migration Studies, 38(9), 1333-1338.

62. Potts, R., Behrensmeyer, A. K., Faith, J. T., Tryon, C. A., Brooks, A. S., Yellen, J. E., et al. (2018). Environmental dynamics during the onset of the Middle Stone Age in eastern Africa. Science, 360(6384), 86-90.

63. Lempert, R., Scheffran, J., \& Sprinz, D. F. (2009). Methods for long-term environmental policy challenges. Global Environmental Politics, 9(3), 106-133.

64. Sakamoto, T. (2016). Computational research on mobile pastoralism using agent-based modeling and satellite imagery. PLOS ONE, 11(3), e0151157. https://doi.org/10.1371/journal.pone.01511 57.

65. Sallach, D. L. (2003). Social theory and agent architectures. Social Science Computer Review, 21(2), 179-195.

66. Salpeteur, M., Patel, H., Balbo, A. L., Rubio-Campillo, X., Madella, M., Ajithprasad, P., et al. (2015). When knowledge follows blood. Current Anthropology, 56(3), 471-483.

67. Schaub, M. L. (2012). Lines across the desert: mobile phone use and mobility in the context of trans-Saharan migration. Information Technology for Development, 18(2), 126-144.

68. Scheffran, J., Marmer, E., \& Sow, P. (2012). Migration as a contribution to resilience and innovation in climate adaptation: social networks and co-development in Northwest Africa. Applied Geography, 33, 119-127.

69. Seagren, C. W. (2015). A replication and analysis of tiebout competition using an agent-based computational model. Social Science Computer Review, 33(2), 198-216.

70. Sheller, M., \& Urry, J. (2006). The new mobilities paradigm. Environment and Planning A, 38, 207-226.

71. Squazzoni, F., Jager, W., \& Edmonds, B. (2014). Social simulation in the social sciences. Social Science Computer Review, 32(3), 279-294.

72. Suleimenova, D., Bell, D., \& Groen, D. (2017). A generalized simulation development approach for predicting refugee destinations. Scientific reports, 7(1), 13377.

73. Tambuscio, M., Oliveira, D. F. M., Ciampaglia, G. L., \& Ruffo, G. (2018). Network segregation in a model of misinformation and fact-checking. Journal of Computational Social Science, 1(2), 261-275.

74. Thalang, C. N., \& Auikool, C. (2018). The immobility paradox in Thailand's southern border provinces. South East Asia Research, 26(4), 315-329.

75. Urry, J. (2007). Mobilities. Cambridge: Polity Press.

76. Whallon, R., Lovis, W. A., \& Hitchcock, R. K. (2011). Information and its role in hunter-gatherer bands. Los Angeles: UCLA/Cotsen Institute of Archaeology Press.

77. Wilensky, U., \& Rand, W. (2015). An introduction to agent-based modeling: modeling natural, social, and engineered complex systems with NetLogo. Cambridge: MIT Press.

78. Winterhalder, B., Lu, F., \& Tucker, B. (1999). Risk-sensitive adaptive tactics: models and evidence from subsistence studies in biology and anthropology. Journal of Archaeological Research, 7(4), $301-348$.

Publisher's Note Springer Nature remains neutral with regard to jurisdictional claims in published maps and institutional affiliations. 


\section{Authors and Affiliations}

\section{Juan Miguel Rodriguez-Lopez ${ }^{1}$ (D) . Meike Schickhoff ${ }^{2} \cdot$ Shubhankar Sengupta $^{3}$. Jürgen Scheffran ${ }^{1}$}

Meike Schickhoff

meike.schickhoff@mpimet.mpg.de

Shubhankar Sengupta

shubhankar.sengupta@hzg.de

Jürgen Scheffran

juergen.scheffran@uni-hamburg.de

1 Research Group Climate Change and Security (CLISEC), Institute of Geography, University of Hamburg, Hamburg, Germany

2 Max-Planck Institute for Meteorology, Hamburg, Germany

3 Climate Service Center Germany (GERICS), Helmholtz-Zentrum Geesthacht, 20095 Hamburg, Germany 